\title{
Engaged or Not? A Comparative Study on Factors Inducing Work Engagement in Call Center and Service Sector Work
}

I Armi Mustosmäki'

Researcher, Department of Social Sciences and Philosophy, University of Jyväskylä, Finland.

\section{Timo Anttila'}

Academy research fellow, Department of Social Sciences and Philosophy, University of Jyväskylä, Finland

\section{Tomi Oinas'}

Post-doctoral researcher, Department of Social Sciences and Philosophy, University of Jyväskylä, Finland

\begin{abstract}
The aim of this study was to compare the possibilities of experiencing positive well-being in call centers and other service sector work. The article focuses on the prevalence of working conditions (job demands, autonomy, and social support) in call centers and at other service sector workplaces and how these factors are related to work engagement. In addition, we examine whether the relationships are divergent in call centers in comparison to other service sector work. Analysis is based on the data provided by the "Quality of Life in Changing Europe" project. The survey data were collected from service sector organizations (retail, banking, and insurance) and a telecom organization's call center functions in Finland ( $N=967$ ). According to our results, work engagement in call center environment is challenging due to the strong negative effect of job demands. In general, call center employees experienced less feelings of engagement than employees in the comparison organizations. This difference remained significant even after controlling for background factors and measures of working conditions. In addition, we found significant differences between call center and other service sector organizations in the effects of both autonomy and demands. The levels of autonomy and work demands proved to be strong antecedents of perceived work engagement, especially in call center environment.
\end{abstract}

\section{KEY WORDS}

Autonomy / call center / intensity / job quality / social support / work engagement

\section{Introduction}

- he shifting of varied and complex customer service delivery to call centers has been an economic success story. For example, Batt and Moynihan (2002) state that huge economies of scale have been achieved through office consolidation, service automation, and process rationalization. At the same time, a relatively large body of literature has shown that call centers are specific workplaces which incorporate work

\footnotetext{
${ }^{1}$ Department of Social Sciences and Philosophy, FIN-40014 University of Jyväskylä, Finland.

E-mail: armi.mustosmaki@jyu.fi
} 
conditions that have the potential to negatively affect employee well-being. For the employees, the introduction of Taylorist forms of industrial engineering models in call center environments has meant the experiencing of a degradation in working conditions, the routinization of work processes, boredom, and increased stress, which are associated with the speeding up of job cycle times (Knights and McCabe, 1998; Taylor and Bain, 1999; Taylor et al., 2003).

Although various sociological studies have drawn attention to call centers as offering low-quality and highly controlled "sweat shop" jobs, these notions have also been criticized. The managerial perspective has recognized that call centers do not constitute a workplace entirely devoid of work interest (Rose and Wright, 2005). Call center work may offer opportunities to use various skills, such as communication skills, independent problem solving, multi-tasking, and technical knowledge (Belt et al., 2002; Russell, 2007). Furthermore, actively attending to customers and solving their problems may also be a significant source of job satisfaction (Holman, 2003). In fact, according to Holman (2002), the causes of stress and the levels of well-being of call center employees are similar to workers in comparable clerical and manufacturing jobs.

Although there has been a growing interest to study well-being in call centers, there are few studies that have paid attention to positive work attitudes (Bakker et al., 2003; Grebner et al., 2003; Holman, 2002; Holman et al., 2002; Wegge et al., 2006). Moreover, most studies have concluded that call centers are "unique workplaces" and have concentrated on studying them in isolation and not introduced a comparative element. The aim of this study is to compare the possibilities of experiencing positive well-being, measured as work engagement, in call centers and other service sector work. This article focuses on the prevalence of certain working conditions (job demands, autonomy, and social support) in call centers and at other service sector workplaces in Finland. We examine how these factors are related to work engagement and whether the relationships are divergent in call centers in comparison to other service sector work.

\section{Call center management}

The managerial perspective has recognized how employee well-being and especially their contribution and dedication have become critical business issues. Customer service agents are expected to provide high levels of satisfaction and convenience for customers and make customers feel valued (Kinnie et al., 2000). Customer satisfaction and organizational output are largely dependent on employees' discretionary efforts to comply with organizational goals. In trying to create more output with less employee input, the management has become increasingly interested in how to commit the "hearts and minds" of their employees (Ulrich, 1997; van den Broek, 2004). Accordingly, the attention of researchers has been drawn to examining human resource management issues and the problematic work attitudes prevalent in call center environments, such as absenteeism, low job satisfaction, low performance and turnover, as well as the factors predicting those behaviors (Bakker et al., 2003; Grebner et al., 2003; Hallman et al., 2008; Schalk and Van Rijckevorsel, 2007). Also, much attention has been given to factors that are related to the ill-health of call center employees (Bakker et al., 2003; Charbotel et al., 2009; Croidieu et al., 2008; Zapf et al., 2003). However, most studies have concentrated only on call centers. In fact, only a few studies have compared call center working 
conditions and well-being to other types of work in order to assess whether the conditions of work in call centers are actually inferior (Grebner et al., 2003; Holman, 2002; Zapf et al., 2003). Nevertheless, very little is known about what kind of working conditions are related to positive work attitudes and well-being in the call center environment.

\section{Work engagement and the role of job characteristics}

Modern organizations expect their employees to be proactive and show initiative, take responsibility for their own professional development, and commit to high-quality performance standards. In other words, they need engaged workers (Bakker et al., 2008). This holds true for call center employees as well. In recent organization and work psychology literature, work engagement is seen as a concept that encompasses the central aspects of the positive well-being of workers (Bakker et al., 2007b).

Although there are various definitions of work engagement (or employee engagement in HR and business literature), in this study we rely on the definition supplied by Schaufeli et al. (2002)—which has been widely supported in empirical research. Work engagement is understood as being positive and fulfilling, i.e., an affective-motivational state of work-related well-being that is characterized by vigor, dedication, and absorption (Schaufeli et al., 2002). Vigor refers to energetic working, being ambitious enough to work hard, even in challenging situations. Furthermore, a dedicated worker finds the work meaningful, is inspired and proud of the work she/he does. Absorption refers to personal immersion in work, from which one gets pleasure. It also indicates that a person is concentrated on his/her work and finds it rewarding (Maslach et al., 2001).

Work engagement is not only beneficial for the well-being of the worker but also has several advantages for the functioning of an organization. Work engagement is associated with constructive behaviors such as self-initiative and independent problem solving (Salanova and Schaufeli, 2008) as well as better performance (Halbesleben, 2010; Xanthopoulou et al., 2008) and innovativeness (Schaufeli et al., 2006). Work engagement is also linked to positive work attitudes, such as commitment to an organization (Hakanen et al., 2006, 2008; Halbesleben, 2010) and lower turnover intentions (Halbesleben, 2010; Parzefall and Hakanen, 2010; Schaufeli and Bakker, 2004). Moreover, work engagement has been found to predict the service climate, which, in turn, is positively associated with employee performance and customer loyalty (Salanova et al., 2005). Work engagement has also been linked to an organization's financial profitability (Xanthopoulou et al., 2009). In addition, these processes could be beneficial for teams since the experiencing of work engagement has proven to be "contagious" between colleagues within teams (Bakker et al., 2006).

\section{The antecedents of worker well-being}

Often working conditions in call centers are evaluated as unfavorable for employee well-being and health. More specifically, according to earlier research, call centers are characterized by elements of Taylorism and its emphasis on a strict division of labor, limited complexity and variability, and low employee control over work (Callaghan and Thompson, 2001). According to Karasek's model of employee well-being, workers 
working at workplaces that combine high levels of job demands and low control have increased levels of strain that may lead to stress (Karasek, 1979: 289-290). Karasek's model has since been supplemented with the dimension of social support to create the Job Demand-Control-Support model (Johnson and Hall, 1988; Karasek and Theorell, 1990). In this model, social support refers to social interaction with colleagues and supervisors. Social support is found to be a straightforward resource, in that it is functional in achieving work goals. This helps workers to maintain their motivation (Bakker and Demerouti, 2007).

More specifically, Karasek's model focuses on mental strain by looking at job demands and autonomy. Job demands refer to those psychological stress factors, such as high work pressure, emotional demands, and role ambiguity, that influence how employees manage their workloads, unexpected work tasks, or work conflicts. A job task can potentially produce psychological strain in cases where it exceeds the employee's adaptive capability. In contrast, job resources such as social support, performance feedback, and autonomy can result in a motivational process resulting in job-related learning, work engagement, and organizational commitment (e.g., Bakker and Demerouti, 2007; Demerouti et al., 2001a, 2001b; Salanova et al., 2005). Job autonomy is measured by assessing an employee's possibilities to influence his/her own work arrangements. Further, the model separates two components of job autonomy: skill discretion and decision authority. Skill discretion refers to the possibility to be creative, participate in decision making, learn new things, and use professional skills, whereas decision authority refers to the possibility to choose the way work is performed and to take part in decisions affecting work. In this article, we use the concept of autonomy to cover both daily control over work tasks and skill variety in one's job.

Although the interaction of demands and resources is often the focal point of job stress studies (e.g., Van der Doef and Maes, 1999), it has been introduced also for studies concerning positive well-being, namely work engagement (see, e.g., Bakker et al., 2007a; Hakanen et al., 2008; Mauno et al., 2007). The meta-analysis on the sources of work engagement shows that both job demands and resources are important antecedents of work engagement (Halbesleben, 2010).

\section{Job characteristics inducing work engagement}

Studies examining the antecedents of work engagement have found job resources to be the most robust predictor of experiences of work engagement (Bakker et al., 2007a, 2008; Hakanen et al. 2005; Halbesleben, 2010; Schaufeli and Bakker, 2004; Schaufeli et al., 2009). This connection has been confirmed in longitudinal studies (Hakanen et al., 2008; Mauno et al., 2007). The role of job demands in generating engagement is more ambiguous. Although balance models of employee well-being suggest that job demands could deteriorate the basis of well-being, either by reducing resources or by directly decreasing levels of well-being, this hypothesis might be too simplistic. For example, Karasek's model suggests that job demands are not necessarily harmful. Too few demands might lead to employee boredom. In contrast, some level of effort and dealing with challenges may induce motivational processes and feelings of accomplishment at work. According to Karasek's model, demands are considered detrimental only when 
they exceed the employees' capabilities and are not accompanied by the resources necessary for a task. In other words, a high demand level should also be accompanied with the required amount of job resources in order to promote worker well-being. This interaction effect has gained some support with regard to work engagement. Bakker et al. $(2007 a)$ suggested that job resources as triggers of engagement become salient in the face of high job demands.

\section{Aims, Data and Methods}

\section{Aims}

In this article, we explore how work engagement varies between call center and other service sector employees and is affected by the three factors used for predicting it: demands, autonomy, and social support. In addition, we are interested in whether job quality in call centers is inferior to other service jobs, as much of the literature suggests.

The few comparative studies conducted on call centers have found that there is less variety in work tasks and work discretion given to call center employees, but that stress-inducing factors were not any higher among call center workers compared with other types of service and non-service work (Zapf et al., 2003). The study by Grebner et al. (2003) supports earlier results in terms of low autonomy and skill variety. However, they found task-related stressors, namely time pressure, to be higher among call center workers than among workers in more traditional professions (see also Holman, 2002). Additionally, many non-comparative studies have concluded that call center work environments are stressful due to the strict managerial control experienced by workers (Callaghan and Thompson, 2001; Taylor et al., 2002). Therefore, we assume that the level of job demands is higher and the level of skill variety and job autonomy is lower for call center employees when they are compared with employees working in other service sector organizations.

With regard to social relationships, call centers have been seen as exceptional workplaces. According to Deery et al. (2010), social relationships may be important in interactive service work as they might offer a defense against the abusive practices of management and, in some cases, the excessive demands of customers (see also Mulholland, 2004; Townsend, 2005). In work settings such as service work, where interaction can be intense, employees are likely to seek support from each other and the social setting in order to develop a feeling of control over their work. Hence, we expect to observe higher levels of social support among call center workers than in other service sector jobs.

In addition, we expect to find a lower level of engagement among call center employees due to the fact that earlier studies highlight the meaning of resources, and especially that of job autonomy, with regard to the emergence of feelings of engagement in work (see, e.g., Bakker and Demerouti, 2007; Hakanen and Roodt, 2010). Moreover, previous studies have found weak associations between job demands and engagement (e.g., Hakanen et al., 2008; Halbesleben, 2010). Therefore it will be interesting to see if they do have an effect in the call center environment, which has often been described as a high-pressure, low-autonomy working environment. 


\section{Survey data and the call center environment}

The quantitative analysis on employee experiences is based on the data provided by the Quality of Life in Changing Europe (FP6) project. The survey data were collected from service sector organizations representing retail, banking and insurance, telecommunications, and public hospitals in eight European countries (Finland, Sweden, the Netherlands, Germany, the UK, Portugal, Hungary, and Bulgaria). In this study, we will concentrate only on the Finnish data $(N=967)$, which included a telecom organization's call center functions.

As the data are gathered from four work organizations, they are not representative. Among other call center studies, it has been rather common practice to collect data only from one organization. The question of representativeness is, however, important with regard to comparative research designs based on company studies. Earlier research has shown that differences between companies within the same sector may be as large as differences between different types of work in different sectors (Søderfeldt et al., 1997). Especially company-specific organizational and managerial cultures and practices may have a significant influence on perceived working conditions. Our sample of call center included just one large organization, but it was-as well as data gathering-subdivided into several local organizational units with notable organizational independence. We may expect that our call center sample represented a variety of local organizational cultures and managerial practices.

\section{Call center sample}

The analyses concerning the experience of work in the call center are based on a survey conducted in a Finnish private sector telecommunication company. Overall, 435 telecom employees and managers filled in the online questionnaire (response rate 59\%). The majority of the call center employees were female $(69 \%)$. Over half $(59 \%)$ of the call center agents were between the ages of 20 and 34, and only $8 \%$ were 50 to 64 years old. A supervisory position was held by $10 \%$ of the respondents. Among call center workers, $67 \%$ held indefinite contracts, while only $3 \%$ had fixed term contracts; an additional $26 \%$ were employed via a temporary employment agency. Regarding their family situation, $66 \%$ of the employees were married or cohabiting and a third had children living at home.

\section{Comparison sample}

The comparison group consisted of employees $(N=467)$ working in service sector organizations, representing retail $(N=113)$, banking and insurance $(N=218)$, and health care (public hospital, $N=164$ ). The response rate varied between the organizations (banking 76\%; hospital 47\%; retail 35\%). The majority of employees gave their responses via an online questionnaire. If an employee did not use a PC in his/her daily work, paper questionnaires were distributed to him/her. Women represented the majority of service sector employees $(89 \%)$. The age distribution shows that approximately a third fall into each age category $(20-34,35-49,50-64$ years). A total of $14 \%$ of all 
employees held a supervisory position. The majority of service sector employees $(82 \%)$ worked under indefinite contracts, whereas $17 \%$ had temporary contracts.

\section{Call center characteristics}

The call centers studied belonged to a large Finnish telecom company that operates in a fiercely competitive and rapidly changing market. Call centers are organized into specialized divisions, such as technical support, sales, billing, and customer queries. Most of the employees handle inbound calls. Only few of the services operate around the clock. Assessments of employee output and performance are highly centralized supervisory duties and quantitative measures would appear to be the most important tools. The close monitoring of the employees via strict performance targets, the taping of calls and performance competitions within and between teams coupled with constant attempts to standardize employee behavior possibly add to the stress they experience and leave very little space for the personal autonomy of the employees.

Taken as a whole, changing market orientation, widening product offerings, and quality-driven competition have started to emphasize the skills and abilities of the employees. Employees are expected to adapt to change and quickly learn details concerning new products and technologies. These skills are important not just in technical support but also in other customer service positions. Moreover, technologies related to daily work systems, such as software, are subject to constant development and change in order to facilitate and speed up work flows. These requirements to adapt to constant change pose challenges for the employees. Although these processes might be linked to enhanced variety, complexity, and higher skill levels, they possibly cause extra strain.

The general atmosphere and social relationships in the call centers under study could be described as consensual regardless of the competition within and between teams and the supervisor's role as overseer and coacher of the employees' performances. Employees belong to teams and the function of a team is not only to increase efficiency and to control employees but also to share knowledge and create groups for socializing during leisure time. Nevertheless, due to the nature of the job, work tasks are performed alone.

\section{Key variables}

\section{Work engagement}

Work engagement is a six-item averaged composite variable $(M=4.6, \mathrm{SD}=1.33, \alpha=$ 0.950), the variance of which we try to explain in this study. ${ }^{1}$ It is a slightly modified version of the one found in the study by Schaufeli et al. (2006). The first two components (I feel I'm bursting with energy; When I get up in the morning, I feel like going to work) are descriptive of vigor, the next three (I am enthusiastic about my job; My job inspires me; I am proud of the work that I do) measure job dedication, and the last one (I feel happy when I am working intensely) is indicative of absorption. The response scale of questions ranged from 1 = never to 7 = always. 


\section{Predictors of work engagement}

Work demands. To measure work demands, we use an averaged sum variable $(M=2.7$, $\mathrm{SD}=0.47, \alpha=0.758)$ that is a shortened version of the multiple scale used by Karasek and Theorell (1990) in their Demand-Control-Support model. It includes five statements as follows: Does your job require you to work fast? Does your job require you to work very hard? Do you feel that your job requires too much input from you? Do you have enough time to complete your job? Does your job often make conflicting demands on you? Receiving high scores on this scale indicates that employees feel high pressure in terms of time, and physical and mental effort. The scale of questions ranged from $1=$ never to 4 = always.

Work autonomy (Control over work, time, and place). Work autonomy is an averaged sum variable $(M=1.9, \mathrm{SD}=0.42, \alpha=0.757)$ comprised of eight statements, such as: Are you free to decide what your job involves? and Does your job require you to invent your own tasks? These statements are also adopted from Karasek and Theorell (1990). High scores on this sum variable indicate greater independence in organizing work and using skills at work. The response scale ranged from $1=$ never to 4 = always.

Social support. The social support measure $(M=3.8, \mathrm{SD}=0.55, \alpha=0.676)$ is adopted from Karasek and Theorell (1990). In our study, it consists of five statements: There is a good spirit of unity; My colleagues are there for me; People understand that I can have a bad day; I get on well with my superiors; I get on well with my colleagues. This averaged composite variable is used to measure the general supportiveness of an organization's culture. The response scale of questions ranged from $1=$ strongly agree to 5 = strongly disagree.

\section{Other variables}

In addition to work demands, autonomy, and support measures, we use control variables that are related to personal factors such as gender (dummy coded so that 0 represents men and 1 represents women), age, education $(0=$ less than tertiary, $1=$ tertiary), married/living together $(0=$ no, $1=$ yes $)$, children at home $(0=$ no, $1=$ yes $)$, and work-related factors, such as supervisory position $(0=$ no, $1=$ yes $)$, and temporary contract $(0=$ no, 1 = yes $)$.

\section{Methods}

Both descriptive methods and multiple regression analysis are used to study job quality in call centers and in other service sector organizations. First, descriptive methods are deployed to describe the level of job demands, job resources, and social support. Second, we use hierarchical multiple regression analysis for modeling the connections between demands, autonomy, and support for work engagement. Regression analysis is conducted separately to service sector and call center. In addition, analysis is repeated for whole sample and includes interaction terms for call center dummy with demands, autonomy, and social support. 


\section{Results}

In order to observe whether the levels of work engagement as well as job demands and resources vary among call center and service sector employees, the results of the comparisons of the means are presented in Tables $1-4$.

\section{Work engagement}

According to the engagement index, the possibilities of experiencing work engagement are demonstrably lower among call center workers compared with other service sector employees. The analysis of each question separately does not significantly alter the results. Employees in other service sector jobs report that they are more likely to have frequent feelings of dedication and absorption, they are more proud of the work they always do, and feel more often happy while working. In terms of vigor, the difference between the comparison groups is slightly smaller. The results show that the opportunities for engagement in call center work seem significantly lower when compared with other types of service work.

Table I Work engagement in call centers and other service sector organizations.

\begin{tabular}{|c|c|c|c|c|}
\hline & $\begin{array}{l}\text { Service } \\
\text { Sector }\end{array}$ & $\begin{array}{c}\text { Call } \\
\text { Center }\end{array}$ & $F$ & $\eta$ \\
\hline At my work, I feel bursting with energy & 4.76 & 4.05 & $67.9 * * * *$ & 0.265 \\
\hline When I get up in the morning, I feel like going to work & 4.86 & 4.01 & $70.9 * * * *$ & 0.270 \\
\hline I am enthusiastic about my job & 5.21 & 4.25 & $\mid 10.7^{* * * * *}$ & 0.331 \\
\hline My job inspires me & 4.97 & 4.01 & 106.0***** & 0.325 \\
\hline I am proud of the work that I do & 5.50 & 4.35 & | $33.4^{*} * * *$ & 0.360 \\
\hline I feel happy when I am working intensely & 5.17 & 4.21 & $100.6 * * * *$ & 0.318 \\
\hline Work engagement index & 5.07 & 4.15 & 123.8***** & 0.348 \\
\hline
\end{tabular}

Note: Response categories range from $1=$ never to $7=$ always.

Significance at $* p<0.05$; $* * p<0.01$; $* * * *<<0.00$ I.

\section{Job resources}

\section{Autonomy}

Due to its interactive nature, service sector work in general is characterized by rather low levels of employee control over working time, place, or content. However, compared with other service sector workers, call center employees report even fewer opportunities to influence their jobs, which is a finding that provides support for earlier claims about the restricted task discretion and low task variety afforded to the employees in 
call centers (Grebner et al., 2003; Taylor et al., 2003; Zapf et al., 2003). The most notable differences are found between the comparison groups when the autonomy index is disaggregated. Especially, call center employees felt that they could less often influence what their jobs involve and how their job is done in comparison to employees in other service jobs. When examining the skill aspects of the autonomy index, it is noticeable that call center work does not deviate much from other industry branches in the service sector. Call center employees do report fewer opportunities to use their creativity, but it is notable that there are no statistically significant differences between the perceptions of call center and other service sector employees with respect to the repetitiveness of their jobs. Both groups of employees report that their jobs involve highly repetitive tasks. Moreover, call center employees report having similar opportunities to learn new things as other service sector workers.

Table 2 Job autonomy and skill variety in call centers and other service sector organizations.

\begin{tabular}{|c|c|c|c|c|}
\hline & $\begin{array}{l}\text { Service } \\
\text { Sector }\end{array}$ & $\begin{array}{l}\text { Call } \\
\text { Center }\end{array}$ & $F$ & $\eta$ \\
\hline Do you get to learn new things in your job? & 2.83 & 2.78 & 1.2 & 0.037 \\
\hline Does your job require creativity? & 2.61 & 2.37 & $26.3 * * * *$ & 0.169 \\
\hline Does your job involve repetitive tasks? & 3.18 & 3.20 & 0.2 & 0.014 \\
\hline Are you free to decide how your job is to be done? & 2.69 & 2.18 & 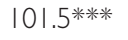 & 0.319 \\
\hline Are you free to decide what your job involves? & 1.90 & 1.43 & 108.4****** & 0.328 \\
\hline Does your job require you to invent your own tasks? & 1.69 & 1.30 & $75.0 * * * * *$ & 0.277 \\
\hline Are you free to decide when you do your work? & 1.60 & 1.60 & 0.0 & 0.003 \\
\hline $\begin{array}{l}\text { Are you free to decide to work wherever is best for } \\
\text { you, either at home or at work? }\end{array}$ & 1.09 & 1.26 & $26.0 * * * *$ & 0.168 \\
\hline Autonomy index & 2.03 & 1.84 & 47.7******* & 0.224 \\
\hline
\end{tabular}

Note: Response categories range from $1=$ never to $4=$ always.

Significance at $* p<0.05$; $* * 00.01$; $* * * * 00.00$ I.

Social support The combined index of social support at the workplace does not reveal any differences between the call center environment and other types of service sector work communities. When we examine the individual variables, the variations between the two groups are found to be rather small. Nearly everyone feels that they are getting along well with their colleagues. In addition, fluent cooperation with supervisors seems to be on a very high level, although somewhat fewer call center employees agree with the statement "I get on well with my supervisors" than other service sector employees.

With regard to having a good spirit of unity, there are no statistically significant differences but call center employees perceive that they get more support from their colleagues than employees in other service sectors. 
Table 3 Social support in call centers and other service sector organizations.

\begin{tabular}{lcccc}
\hline & $\begin{array}{c}\text { Service } \\
\text { Sector }\end{array}$ & $\begin{array}{c}\text { Call } \\
\text { Center }\end{array}$ & $F$ & $\eta$ \\
\hline There is a good spirit of unity & 3.86 & 3.78 & 1.6 & 0.042 \\
\hline My colleagues are there for me & 3.06 & 3.41 & $27.5 * * *$ & 0.173 \\
\hline People understand that I can have a bad day & 3.68 & 3.63 & 0.9 & 0.031 \\
\hline I get on well with my superiors & 4.24 & 4.12 & $5.9 *$ & 0.08 I \\
\hline I get on well with my colleagues & 4.37 & 4.40 & 0.5 & 0.023 \\
\hline Social support index & 3.84 & 3.87 & 0.7 & 0.028 \\
\hline
\end{tabular}

Note: Response categories range from I = strongly disagree to 5 = strongly agree.

Significance at $* p<0.05$; $* * p<0.01$; **** $p<0.001$.

Job demands Job demands were assessed through five questions related to the different sources of pressure experienced at work. Overall, call center employees seem to report a higher level of pressure when comparing the sum index mean to other service sector workers. The difference does not seem very large but it is statistically significant. By further examining the individual statements about demands, more detailed information is acquired. The tempo of work in call centers appears to be very high as call center workers reported more often being required to work fast compared with other service sector employees. This is also reflected in the statements of whether the demands exceed individual performance limits. Call center workers felt more often that their job required too much input from them compared with other service sector employees. However, there is only a small difference between call center and service sector employees in terms of being required to work very hard. These results are in line with earlier studies that highlight the high demands and stressful aspects of call center jobs (Grebner et al., 2003).

Table 4 Job demands in call centers and other service sector organizations.

\begin{tabular}{lcccc}
\hline & $\begin{array}{c}\text { Service } \\
\text { Sector }\end{array}$ & $\begin{array}{c}\text { Call } \\
\text { Center }\end{array}$ & $F$ & $\eta$ \\
\hline Does your job require you to work fast? & 2.97 & 3.25 & $46.3 * * *$ & 0.221 \\
Does your job require you to work very hard & 3.08 & 3.18 & $5.4 *$ & 0.077 \\
$\begin{array}{l}\text { Do you feel that your job requires too much input from } \\
\text { you? }\end{array}$ & 2.21 & 2.37 & $11.5 * *$ & 0.113 \\
Do you have enough time to complete your job? & 2.45 & 2.36 & 3.6 & 0.063 \\
Does your job often make conflicting demands on you? & 2.25 & 2.43 & $18.2 * * *$ & 0.141 \\
\hline Demand index & 2.61 & 2.77 & $26.1 * * * *$ & 0.168 \\
\hline
\end{tabular}

Note: Response categories range from I = never to $4=$ always.

Significance at $* p<0.05 ; * * p<0.01 ; * * * *<<0.001$. 


\section{Results from the regression analysis}

Hierarchical regression analyses for work engagement are presented in Table 5. The analyses were implemented separately for other service sector employees and for call center employees. The regression model consists of three steps. First, the respondents' personal characteristics, gender, age, marital status, and possible children living at home

Table 5 Hierarchical Regression Analysis for Work Engagement.

\begin{tabular}{|c|c|c|c|}
\hline & $\begin{array}{l}\text { Service sector } \\
\text { employees }\end{array}$ & $\begin{array}{l}\text { Call center } \\
\text { employees }\end{array}$ & Total sample \\
\hline \multicolumn{4}{|l|}{ Step I } \\
\hline Gender (0 = man, I = woman $)$ & -0.04 & 0.05 & $0.07 *$ \\
\hline Age & 0.19 ****** & $0.18 * *$ & $0.27 * * * * *$ \\
\hline Married (0 = no, I = yes $)$ & -0.03 & 0.02 & -0.02 \\
\hline Children at home ( $0=$ no, $1=$ yes $)$ & 0.04 & 0.08 & $0.07 *$ \\
\hline$\Delta R^{2}$ & $0.043 * *$ & $0.061 * * * *$ & $0.101 * * * *$ \\
\hline \multicolumn{4}{|l|}{ Step 2} \\
\hline Supervisory position ( $0=$ no, $1=$ yes $)$ & $0.13^{*}$ & $0.29 * * * *$ & 0.21 ****** \\
\hline Tertiary education ( $0=$ no, $1=$ yes $)$ & 0.03 & 0.01 & 0.02 \\
\hline Temporary contract ( $0=$ no, I=yes) & $0.13 *$ & $0.11 *$ & $0.10 * *$ \\
\hline$\Delta R^{2}$ & $0.029 * *$ & $\left.0.08\right|^{*} * * * *$ & $0.045 * * * *$ \\
\hline \multicolumn{4}{|l|}{ Step 3} \\
\hline Demands & $-0.13^{* * *}$ & $-0.26 * * *$ & $-0.23 * * * *$ \\
\hline Autonomy & $0.36 * * * *$ & $0.39 * * * *$ & $0.40 * * * *$ \\
\hline Support & $0.22 * * * *$ & $0.11 * *$ & $0.15^{* * * * *}$ \\
\hline$\Delta R^{2}$ & $0.188 * * * *$ & 0.268 ***** & 0.250 ***** \\
\hline \multicolumn{4}{|l|}{ Step 4} \\
\hline Call center $(0=$ no, $1=$ yes $)$ & & & $-0.15 * * *$ \\
\hline$\Delta R^{2}$ & & & 0.018 ***** \\
\hline \multicolumn{4}{|l|}{ Step 5} \\
\hline Demands $\times$ call center (interaction) & & & $-0.10 *$ \\
\hline Autonomy $\times$ call center (interaction) & & & $0.13 * *$ \\
\hline Support $\times$ call center (interaction) & & & -0.04 \\
\hline$\Delta R^{2}$ & & & $0.01 \mid$ *** \\
\hline$R^{2}$ & 0.259 & 0.411 & 0.431 \\
\hline N & 447 & 431 & 878 \\
\hline
\end{tabular}

Note: Significance at $* p<0.05$; $* * 0<0.0$ I; $* * * *<<0.00$ I.

Standardized regression coefficients. 
were added to the model. In the second phase, we added respondent's educational level and factors that describe position in the organization: whether they work in a supervisory position and whether they have temporary employment contract. In the third step, we added main predictors, demands, autonomy, and social support to the model. The interaction between job demands and resource factors was also tested but proved to be statistically insignificant, and thus was excluded from the final model. It follows from this that we will mainly concentrate on the exploration of the main effects. In addition for group-level analyses, the table presents a model for the whole sample. This model includes five steps. The first three steps are identical to the one mentioned above, the fourth step includes call center dummy, and the fifth adds interaction terms for call center dummy with demands, autonomy, and social support. A statistically significant interaction means that the effect sizes differ between the call center and service sector. The interaction effects are depicted in Figures 1 and 2.

The background factors included in the model in the first and second step explain the variation in work engagement only modestly. (explanation power $R^{2}$, which is less than $7 \%$ in both samples). Women perceived themselves to be more engaged in their work than men, but this connection was statistically significant only in the whole sample. The observed gender difference is in line with earlier studies (Mauno et al., 2007). Marital status or having children living at home had no significant effect on work engagement in subsamples. However, having children increased work engagement significantly in the whole sample. Mauno et al. (2007) have found similar effects. In addition, age was found to affect work engagement as older employees are more likely to be engaged in their work than their younger colleagues. Mauno et al. (2007) did not find age to have any association with work engagement. Thus, in our study, work engagement

Figure I: Interaction effects of call center and autonomy on work engagement.

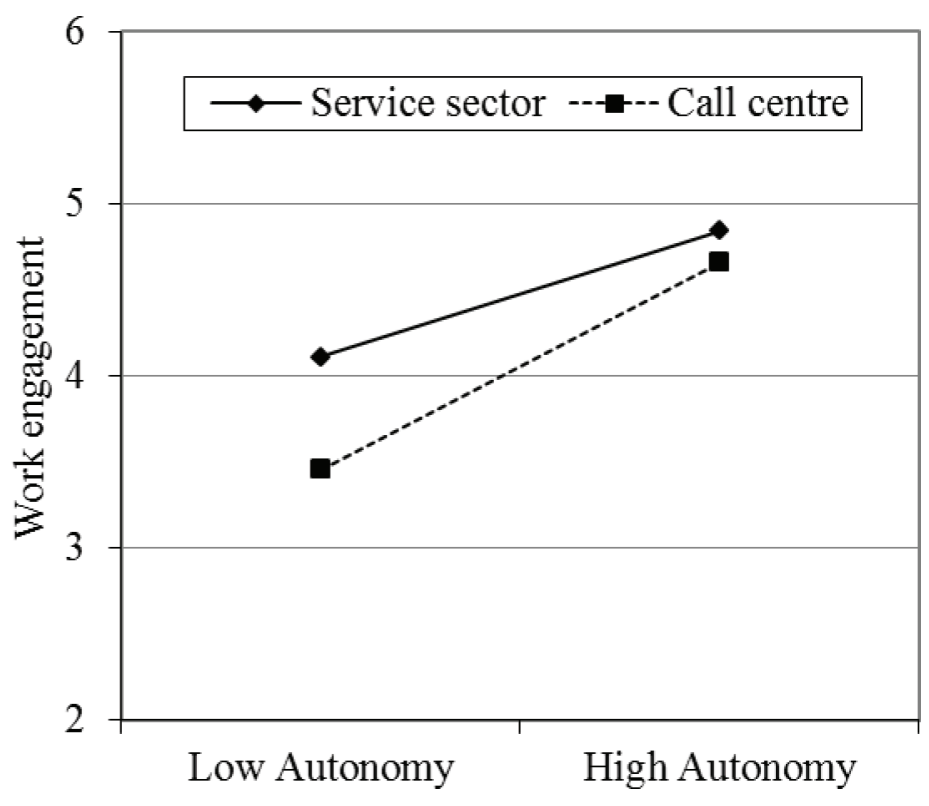


Figure 2: Interaction effects of call center and demands on work engagement.

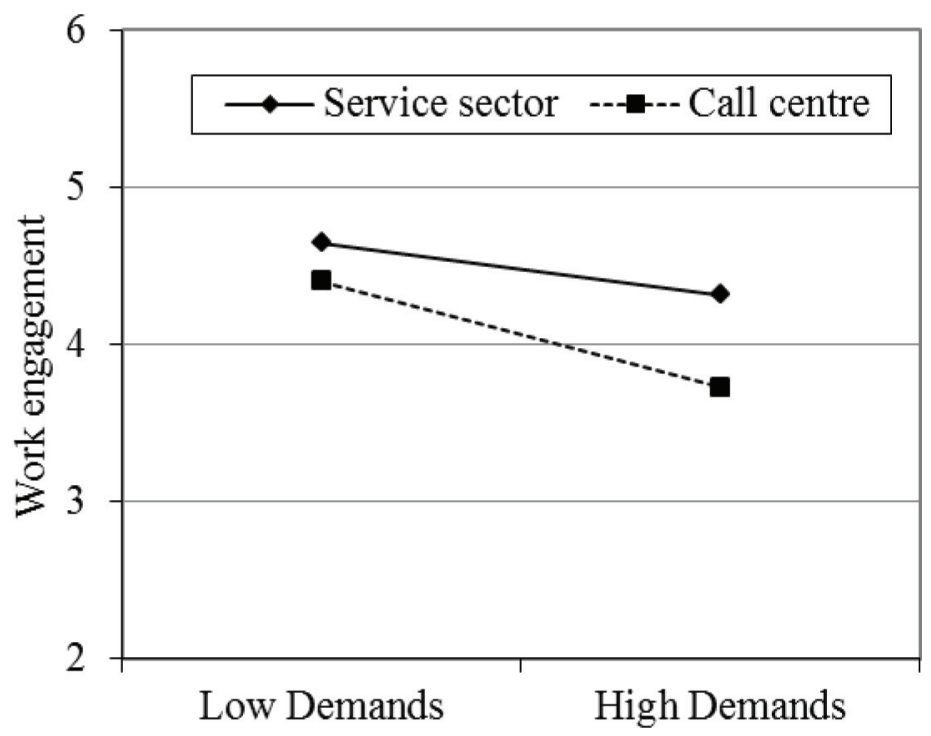

relates mainly to work condition factors. Yet, rather unexpectedly, educational level had no effect on perceived work engagement. A supervisory position had a significant effect on work engagement in both subsamples, but effect seems to be stronger in call centers. Bakker et al. (2003) have also found supervisors in call centers to be more dedicated and committed than customer service workers. Overall, the results gained by adding in background factors contradict previous findings and explain very little of the variation in engagement, which again indicates that we should concentrate more on job characteristics.

The underlying theoretical model for our study was adapted from Karasek and Theorell (Karasek, 1979; Karasek and Theorell, 1990). The adjusted $R$-scores indicate that the model fits the call center in a different way to the way it fits other service sector organizations. The multivariate model explained $41 \%$ of the total variation of the work engagement variable in call centers. The model fit was clearly poorer $(26 \%)$ for our comparison group.

We found some statistically significant differences in the ways in which demands and autonomy affect work engagement in the different work environments of these two comparison groups. In our data, job autonomy was found to be the best predictor of work engagement in both samples. The positive effect of autonomy was even stronger in call centers where the level of discretion was low compared with other service sector organizations (Figure 1). In this respect, our results are in line with previous studies which stress that job resources are found to predict work engagement better than job demands (e.g., Mauno et al., 2007). Also, social support from supervisors and colleagues is expected to enhance work engagement and can be considered another set of job resources (e.g., Halbesleben, 2010). As anticipated, social support was positively associated with work engagement in both groups, but there was no difference in this effect between groups. Whereas earlier studies found mainly weak connections between job 
demands and engagement (e.g., Hakanen et al., 2008), the negative effect of demands on engagement was notable, especially among call center employees (Figure 2). It is also evident from both figures that employees in call center have lower level of work engagement than employees in other service sectors even after controlling for background factors, job demands, autonomy, and social support.

\section{Discussion}

Although it has been acknowledged that service work in general is of lower quality and that this sector of employment has been affected by service sector Taylorism, call center work still appears to be an exceptional case. In the samples studied, call center employees reported higher demands and lower autonomy and social support than employees in other service sector organizations. The findings of this study give support to studies indicating that call centers are characterized by elements of Taylorism, such as limited complexity as well as lower control over the pace of work and work methods (e.g., Taylor et al., 2003). Moreover, our results contradict Holman (2002) who has argued that levels of well-being are similar in call center and comparable clerical and factory jobs. In our comparative data, call center employees did not appear to have stronger social relationships. The result could be seen as unanticipated in the light of earlier studies that highlight the importance of social support, teams, and team building in call centers. Social relationships and the social support they provide have been referred to as coping mechanism against a culture of surveillance (e.g., Deery et al., 2010). We found that social support had a similar boosting effect to work engagement among call center workers and other service sector employees.

According to our results, inducing positive work-related well-being in a regimented call center environment is challenging. In general, call center employees experienced less feelings of engagement than employees in the comparison organizations. According to the regression analysis, autonomy was a significant precursor of the engagement experiences in both groups studied. Moreover, when compared with earlier studies and to the comparison group, work demands resulted in an exceptionally strong negative association with engagement in call centers. In other words, intense work pressure seems to reduce the experience of positive well-being especially in the call centers.

These findings could have practical implications for the organization of work in similarly demanding work environments. Our results suggest that in order to improve work engagement, job demands (particularly time-related pressures) should be reduced and task discretion increased by decreasing managerial control and standardization, in order to induce processes which lead to work engagement. Given that the management of interactive service work relies on the need to elicit tacit skills which deliver quality output as well as specified quantities of output, it is not surprising that coercive and direct control may be counterproductive (van den Broek, 2004). Our results also lead us to question whether social support would be a meaningful resource in a highly demanding work environment as some literature suggests. Our research suggests that organizations should reflect on whether concentrating organizational efforts on the development of social relationships by team building and "having fun" is an effective way to buffer the negative effects of an environment that is highly controlled and competitive, which is something other managerial studies propose (see, e.g., Kinnie et al., 2000). 
Work engagement is a concept that consists of rather intrinsic types of satisfaction and commitment. It could be the case that those employees whose well-being is not hampered by a call center working environment are those who have more extrinsic orientations and attitudes toward work and use these as sources of well-being. The concept of work engagement might not capture the motivation and well-being which relates to pay incentives, the reaching of performance targets, and, for instance, secure employment. Therefore, the issue of well-being at work, especially in a call center environment, should be studied with wider and more multifaceted concepts.

Appendix Bivariate correlations between independent and dependent variables.

\begin{tabular}{|c|c|c|c|c|c|c|c|c|c|c|c|}
\hline & A & B & C & D & $E$ & $F$ & G & $\mathrm{H}$ & I & K & $L$ \\
\hline $\begin{array}{l}\text { A. Work } \\
\text { engagement }\end{array}$ & I & & & & & & & & & & \\
\hline B. Call center & $-0.34 *$ & I & & & & & & & & & \\
\hline C. Female & $0.13^{*}$ & $-0.2 I^{*}$ & I & & & & & & & & \\
\hline D. Age & $0.30 *$ & $-0.35 *$ & $0.19 *$ & I & & & & & & & \\
\hline E. Married & $0.08 *$ & $-0.11 *$ & 0.04 & $0.16^{*}$ & I & & & & & & \\
\hline F. Children & $0.14^{*}$ & $-0.12 *$ & $0.11^{*}$ & $0.22 *$ & $0.20 *$ & I & & & & & \\
\hline G. Supervisor & $0.23^{*}$ & $-0.06 *$ & $-0.12 *$ & $0.17 *$ & $0.16 *$ & $0.10 *$ & I & & & & \\
\hline $\begin{array}{l}\text { H. Tertiary } \\
\text { education }\end{array}$ & -0.04 & $0.08 *$ & $-0.08^{*}$ & $-0.29 *$ & 0.03 & $-0.10 *$ & $0.11 *$ & I & & & \\
\hline $\begin{array}{l}\text { I. Temporary } \\
\text { contract }\end{array}$ & $-0.09 *$ & $0.18 *$ & $-0.16^{*}$ & $-0.43 *$ & $-0.13^{*}$ & $-0.18^{*}$ & $-0.20 *$ & $0.15 *$ & I & & \\
\hline J. Demands & $-0.27 *$ & $0.17^{*}$ & $0.08^{*}$ & $0.11 *$ & 0.01 & 0.01 & $0.08 *$ & -0.05 & $-0.09 *$ & 1 & \\
\hline K. Autonomy & $0.51^{*}$ & $-0.22 *$ & -0.02 & $0.27 *$ & $0.15 *$ & $0.15 *$ & $0.42 *$ & 0.05 & $-0.23^{*}$ & $-0.10^{*}$ & I \\
\hline L. Support & $0.20 *$ & 0.03 & $-0.13^{*}$ & $-0.14 *$ & 0.01 & $-0.08 *$ & $0.06 *$ & 0.05 & $0.07 *$ & $-0.20 *$ & $0.12 *$ \\
\hline
\end{tabular}

* Statistically significant at 0.05 level (two-tailed test).

$N=878$.

\section{References}

Bakker, A. and Demerouti, E. (2007) 'The job demands-resources model: The state of art'. Journal of Managerial Psychology 22(3): 309-328.

Bakker, A., Demerouti, E., and Schaufeli, W. (2003) 'Dual processes at work in a call centre: An application of the job demands-resources model'. European Journal of Work and Organizational Psychology 12(4): 393-417.

Bakker, A., Van Emmerik, I.J., and Euwema, M. (2006) 'Crossover of burnout and engagement in work teams'. Work \& Occupations 33: 464-489.

Bakker, A., Hakanen, J., Demerouti, E., and Xanthopoulou, D. (2007a) 'Job resources boost work engagement, particularly when job demands are high'. Journal of Educational Psychology 99: 274-284. 
Bakker, A., Schaufeli, W., Demerouti, E., and Euwema, M.C. (2007b) An organisational and social psychological perspective on burnout and work engagement. In W. Stroebe and M. Hewston (eds.) The scope of social psychology: Theory and applications: Essays in honour of Wolfgang Stroebe. Hove: Psychology Press, 227-251.

Bakker, A., Schaufeli, W., Leiter, M., and Taris, T. (2008) 'Work engagement: An emerging concept in occupational health psychology'. Work \& Stress 22(3): 187-200.

Batt, R., and Moynihan, L. (2002) 'The viability of alternative call centre production models'. Human Resource Management Journal 1(4): 14-34.

Belt, V., Richardson, R., and Webster, J. (2002) 'Women, social skill and interactive service work in telephone call centres'. New Technology, Work and Employment 17(1): 20-34.

Callaghan, G., \& Thompson, P. (2001) 'Edwards revisited: Technical control and call centres'. Economic and Industrial Democracy 22(1): 13-37.

Charbotel, B., Croidieu, S., Vohito, M., Guerin, A.-C., Renaud, L., Jaussaud, J., Bourboul, C., Imbard, I., Ardiet, D., and Bergeret, A. (2009) 'Working conditions in call-centers, the impact on employee health: A transversal study. Part II'. International Archives of Occupational and Environmental Health 2: 747-756.

Croidieu, S., Charbotel, B., Vohito, M., Renaud, L., Jaussaud, J., Bourboul, C., Ardiet, D., Imbard, I., Guerin, A.-C., and Bergeret, A. (2008) 'Call-handlers' working conditions and their subjective experience of work: A transversal study'. International Archives of Occupational and Environmental Health 82: 67-77.

Deery, S., Iverson, R., and Walsh, J. (2010) 'Coping strategies in call centres: Work intensity and the role of co-workers and supervisors'. British Journal of Industrial Relations 48(1): 181-200.

Demerouti, E., Bakker, A., De Jonge, J., Janssen, P., and Schaufeli, W. (2001a) 'Burnout and engagement at work as a function of demands and control'. Scandinavian Journal of Work Environment Health 27(4): 279-286.

Demerouti, E., Bakker, A., Nachreiner, F., and Schaufeli, W. (2001b) 'The job demandsresources model of burnout', Journal of Applied Psychology 86(3): 499-512.

Grebner, S., Semmer, N., de Faso, L., Gut, S., Kälin, W., and Elfering, A. (2003) 'Working conditions, well-being and job related attitudes among call center agents', European Journal of Work and Organizational Psychology 12(4): 341-365.

Hakanen, J., Bakker, A., and Demerouti, E. (2005) 'How dentists cope with their job demands and stay engaged: The moderating role of job resources'. European Journal of Oral Sciences 113: 479-487.

Hakanen, J., Bakker, A., and Schaufeli, W. (2006) 'Burnout and work engagement among teachers'. Journal of School Psychology 43(6): 495-513.

Hakanen, J., and Roodt, G. (2010) Using job demands and resources model to predict the engagement: Analysing a conceptual model. In A. Bakker \& M. Leiter (eds.) Work engagement. A handbook of essential theory and research (pp. 85-101). New York: Psychology Press.

Hakanen, J., Schaufeli, W., and Ahola, K. (2008) 'The job demands-resources model: A threeyear cross-lagged study of burnout, depression, commitment, and work engagement'. Work \& Stress 22(3): 224-241.

Halbesleben, J. (2010) A meta-analysis of work engagement: Relationships with burnout, demands, resources, and consequences. In A. Bakker and M. Leiter (eds.) Work engagement. A handbook of essential theory and research (pp. 102-117). New York: Psychology Press.

Hallman, D., Frenkel, S., Sorensen, O., and Wood, S. (2008) 'Work design variation and outcomes in call centers: Strategic choice and institutional explanations'. Industrial \& Labor Relations Review 62: 510-510.

Holman, D. (2002) 'Employee well-being in call centres'. Human Resource Management Journal 12(4): 35-50.

Holman, D. (2003) 'Phoning in sick? An overview of employees stress in call centres'. Leadership \& Organization Development Journal 24(3): 123-130. 
Holman, D., Chissick, C., and Totterdell, P. (2002) 'The effects of performance monitoring on emotional labor and well-being in call centers'. Motivation and Emotion 26(1): 57-81.

Johnson, J., and Hall, E. (1988) 'Job strain, work place social support, and cardiovascular disease: A cross-sectional study of a random sample of the Swedish working population'. American Journal of Public Health 78(10): 1336-1342.

Karasek, R. (1979) 'Job demands, job decision latitude, and mental strain: Implications for fob redesign'. Administrative Science Quarterly 24(2): 285-308.

Karasek, R., and Theorell, T. (1990) Healthy work: Stress, productivity, and the reconstruction of working life. New York: Basic Books.

Kinnie, N., Hutchinson, S., and Purcell, J. (2000) “"Fun and surveillance”: The paradox of high commitment management in call centres'. International Journal of Human Resource Management 11(5): 967-985.

Knights, D., and McCabe, D. (1998) 'What happens when the phone goes wild? Staff, stress and spaces for escape in a BPR regime'. Journal of Management Studies 35(2): 163-194.

Maslach, C., Schaufeli, W., and Leiter, M. (2001) 'Job burnout'. Annual Review of Psychology 52(1): 397-422.

Mauno, S., Kinnunen, U., and Ruokolainen, M. (2007), 'Job demands and resources as antecedents of work engagement'. Journal of Vocational Behaviour 70: 149-171.

Mulholland, K. (2004) 'Workplace resistance in an Irish call centre: Slammin', scammin', smokin' an' leavin". Work, Employment and Society 18(4): 709-772.

Parzefall, M.-R., and Hakanen, J. (2010) 'Psychological contract and its motivational and health-enhancing properties'. Journal of Managerial Psychology 25(1): 4-21.

Rose, E., and Wright, G. (2005) 'Satisfaction and dimensions of control among call center representatives'. International Journal of Human Resource Management 16(1): 136-160.

Russell, B. (2007) 'You gotta lie to it: Software applications and the management of technological change in a call center'. New Technology, Work and Employment 22(2): 132-145.

Salanova, M., Agut, S., and Peiró, J.M. (2005) 'Linking organizational facilitators and work engagement to employee performance and customer loyalty: The mediation of service climate'. Journal of Applied Psychology 90: 1217-1227.

Salanova, M., and Schaufeli, W. (2008) 'A cross-national study of work engagement as a mediator between job resources and proactive behavior'. International Journal of Human Resource Management 19(1): 116-131.

Schalk, R., and Van Rijckevorsel, A. (2007) 'Factors influencing absenteeism and intention to leave in a call centre'. New Technology, Work and Employment 22(3): 260-274.

Schaufeli, W., and Bakker, A. (2004) 'Job demands, job resources, and their relationship with burnout and engagement: A multi-sample study'. Journal of Organizational Behavior 25: 293-315.

Schaufeli, W., Bakker, A., and Van Rhenen, W. (2009) 'How changes in job demands and resources predict burnout, work engagement, and sickness absenteeism'. Journal of Organizational Behavior 30: 893-917.

Schaufeli, W., Salanova, M., González-Romá, V., and Bakker, A. (2002) 'The measurement of engagement and burnout: A two sample confirmatory factor analytic approach'. Journal of Happiness Studies 3(1): 71-92.

Schaufeli, W., Taris, T., and Bakker, A. (2006) Dr. Jekyll and Mr. Hide: On the differences between work engagement and workaholism. In R. Burke (ed.) Research companion to working time and work addiction. Cheltenham: Edward Elgar, 193-217.

Søderfeldt, B., Søderfeldt, M., Jones, K., Ocampo, P., Mountaner, C., Ohlson, C.G., and Warg, L.E. (1997) 'Does organization matter? A multilevel analysis of the demand-control model applied to human services'. Social Science and Medicine 44, 527-534. 
Taylor, P., and Bain, P. (1999) 'An assembly line in the head. Work and employee relations in the call centre'. Industrial Relations Journal 30(2): 101-117.

Taylor, P., Baldry, C., Bain, P., and Ellis, V. (2003) 'A unique working environment: Health, sickness and absence management in UK call centres'. Work, Employment and Society 17(3): 435-458.

Taylor, P., Hyman, J., Mulvey, G., and Bain, P. (2002) 'Work organisation and the experience of work in call centres'. Work, Employment and Society 16(1): 101-117.

Townsend, K. (2005) 'Electronic surveillance and cohesive teams: Room for resistance in an Australian call centre'? New Technology, Work and Employment 20(1): 47-59.

Ulrich, D. (1997) Human resource champions. Boston, MA: Harvard Business School.

van den Broek, D. (2004) “"We have the values”: Customers, control and corporate ideology in call centre operations'. New Technology, Work and Employment 19(1): 2-13.

Van der Doef, M., and Maes, S. (1999) 'The job demand-control (-support) model and psychological well-being: A review of 20 years of empirical research'. Work \& Stress 13(2): 87-114.

Wegge, J., Van Dick, R., Fisher, G., Wecking, C., and Moltzen, K. (2006) 'Work motivation, organisational identification, and well-being in call centre work'. Work \& Stress 20(2): 60-83.

Xanthopoulou, D., Bakker, A., Heuven, E., Demerouti, E., and Schaufeli, W.B. (2008) 'Working in the sky: A diary study on work engagement among flight attendants'. Journal of Occupational Health Psychology 13: 345-356.

Xanthopoulou, D., Bakker, A., Heuven, E., Demerouti, E., and Schaufeli, W.B. (2009) 'Work engagement and financial returns: A diary study on the role of job and personal resources'. Journal of Occupational and Organizational Psychology 82: 183-200.

Zapf, D., Isic, A., Bechtoldt, M., \& Blau, P. (2003) 'What is typical for call centre jobs? Job characteristics, and service interactions in different call centres'. European Journal of Work and Organizational Psychology 12(4): 311-340.

\section{End notes}

${ }^{1}$ We also conducted factor analyses in order to test the unidimensionality of all scales. According to scree test of eigen values, one factor solution was best for all scales. The extracted factor explained $80 \%$ of the variance in the variables measuring work engagement. Corresponding figures were $38 \%, 45 \%$, and $51 \%$ for autonomy, social support, and job demands, respectively. 